\title{
BMJ Open Effects of walkability on physical activity and obesity: a prospective observational study protocol
}

\author{
Yalan Zhang, ${ }^{1}$ Siyu Chen, ${ }^{2}$ Jiayang Shi, ${ }^{1}$ Zongtao Chen (1) ${ }^{1}$
}

To cite: Zhang Y, Chen S, Shi J, et al. Effects of walkability on physical activity and obesity: a prospective observational study protocol. BMJ Open 2020;10:e034882. doi:10.1136/ bmjopen-2019-034882

- Prepublication history for this paper is available online. To view these files, please visit the journal online (http://dx.doi org/10.1136/bmjopen-2019034882).

YZ and SC contributed equally.

Received 09 0ctober 2019 Revised 20 August 2020 Accepted 26 August 2020

\section{Check for updates}

(C) Author(s) (or their employer(s)) 2020. Re-use permitted under CC BY-NC. No commercial re-use. See rights and permissions. Published by BMJ.

${ }^{1}$ Health Management Centre, First Affiliated Hospital to Army Medical University, Chongqing, China

${ }^{2}$ Department of Epidemiology and Biostatistics, First Affiliated Hospital to Army Medical University, Chongqing, China

Correspondence to Dr Zongtao Chen; chenzongta0@126.com

\section{ABSTRACT}

Introduction The prevalence of overweight and obesity is increasing worldwide, which could lead to a set of chronic and metabolic diseases. Physical activity is a modifiable factor for obesity, which was reported to be correlated with the built environment. However, the effects of the built environment on physical activity are not consistent. Walkability is a convenient way to assess the built environment. We aim to prospectively explore the relationship among walkability, physical activity and obesity in Chinese participants in Chongqing, a hilly city and provide evidence for future urban planning. Methods and analysis Participants will be recruited from people who receive health examination in the Health Management Centre, the First Affiliated Hospital to Army Medical University. Exposure variables are WalkScores calculated within the areas around workplace and residential addresses of participants. The primary outcomes are body mass index measured through health examination at baseline and follow-ups, and daily walking steps recorded by WeChat mini application for 30 days after every time of health examination. Other healthrelated data of the participants will also be collected. Multivariate regression analysis will be performed to examine the relationship between exposure variables and outcomes.

Ethics and dissemination The Protocol is approved by the Ethics Committee of the First Affiliated Hospital to Army Medical University (KY201839). The results will be actively disseminated through peer-review journals and conference publications.

Registration number Chinese Clinical Trial Registry (ChiCTR1800017680).

\section{INTRODUCTION}

The prevalence of overweight and obesity has doubled worldwide since 1980 , which is currently $5 \%$ in children and $12 \%$ in adults. In 2015, the number of children and adults who suffered from obesity was 107.7 million and 603.7 million, respectively. ${ }^{2}$ High body mass index (BMI), an indicator for obesity, was identified to be a risk factor for various chronic diseases, including cardiovascular disease, diabetes, chronic kidney disease and cancers. ${ }^{2}$ Chinese Health and Nutrition Survey shown the rate of obesity and overweight in adults increased from $25.1 \%$

\section{Strengths and limitations of this study}

This study innovatively evaluates the effects of walkability on physical activity and obesity in a hilly city prospectively.

- The daily walking steps were recorded using a novel method, WeChat mini application.

- This study combines the data collected from the health examination and cellphones.

- One limitation is that WeChat mini application would fail to record daily walking steps during swimming and other physical activities without cellphones.

- The other limitation is the maximum time for data collection is 30 days after one authorisation.

to $39.6 \%$ from 1997 to $2009 .{ }^{3}$ The updated prevalence of overweight and obesity were reported to be $25.8 \%$ and $7.9 \%$, respectively, in $2017 .{ }^{4}$ It is reported that the obesity rate in Chongqing in Southwestern China is $10.3 \% .^{56}$

One of the modifiable risk factors of obesity and chronic diseases is physical inactivity. ${ }^{78}$ Physical activity indicators are correlated with some metabolic indicators. ${ }^{9}$ Physical inactivity is partly due to insufficient activity during leisure time and an increase in sedentary behaviour during occupational and domestic activities. ${ }^{10}$ Additionally, an increase in the use of 'passive' modes of transport such as taking a car or a bus has also been associated with declining physical activity levels, which means less walking or any human-powered movement in daily life. ${ }^{10}$ Insufficient physical activity contributes to $6 \%$ of the disease burden of coronary heart disease, $7 \%$ of that of type 2 diabetes, $10 \%$ of that of breast cancer and $10 \%$ of that of colon cancer. ${ }^{11}$ As reported, more than 533000 deaths and more than 1.3 million deaths could be averted annually by reducing the prevalence of physical inactivity by $10 \%$ and $25 \%$, respectively. ${ }^{11}$ Thus, in order to ameliorate physical inactivity, it is crucial to understand its associated factors and determinants. The 
factors associated with physical activity in high-income countries were reported to be age, sex, health status, selfefficacy, genetic factors and motivation. ${ }^{12}$ At the level of population, the factors outside health sectors have been identified to be causally related to physical inactivity, for example, urban planning, transportation system and the built environment. ${ }^{12-14}$

Walkability is a useful tool in the process of evaluating the effects of the built environment on physical activity. ${ }^{15}$ However, the evidence on the associations among the built environment, walkability, physical activity and health is inconsistent. A study published in Nature in 2017 with more than 700000 participants and 68 million days recorded revealed that higher walkability was associated with more daily walking steps, whose effect was stronger for females. ${ }^{15}$ Porter and colleagues also indicated in a cohort study with 688 participants that as one aspect of the neighbourhood environment, walkability was associated with physical activity among pregnant women. ${ }^{16}$ Other studies from Japan and North America also supported the positive effects of the built environment on physical activity. ${ }^{17-19}$ In a middle size city Bengbu in Eastern China, researchers observed about at least 30\% lower risk of cardiovascular diseases were associated with moderate to high levels of WalkScore, compared with controls with low WalkScore, in which WalkScore is a measure of walkability. ${ }^{20}$ However, a cohort study with 1819 households investigating moving to the former Olympic athletes' village in London discovered no effect associated with this living environment change on daily walking steps, indicating that ameliorating the built environment might be insufficient to enhance physical activity. ${ }^{21}$ A study with 161 older adult participants in Canada also shown that walkability was not associated with physical activity volume or intensity. ${ }^{22} \mathrm{~A}$ study in a small city in China called Yuncheng also showed no positive associations of land-use mix and walking duration. ${ }^{23}$ In addition to these inconsistent evidence, there is no research on walkability effects on physical activity and health in China.

The factors of walkability usually include residential housing units, retail shops, public transportation, streetlevel movement density, the distance to behavior-related destinations. ${ }^{24-29}$ Residential housing units are a house, apartment, group of rooms, or a single room for occupancy as a separate living unit, which could predict the population allocation in an area. ${ }^{30}$ Retail shops are one kind of points of interest, which serve for non-residential uses and can enhance the motivation of walking. ${ }^{25}$ Accessibility, which are represented by the street-level movement density and the distance to behavior-related destinations, as well as the proximate access to public transportation, are crucial characteristics of a walkable neighbourhood. ${ }^{26}$ Some studies also take into account the population density, the street connectivity, land-use diversity, infrastructure and safety for walking, aesthetics and crime influence. ${ }^{27-29}$ WalkScore (www.WalkScore. com) is a user-friendly open composite walkability index. It could evaluate the walkability of a mail address or a city and is widely used in the studies investigating the relationship between walkability and health status. ${ }^{15} 31$

The evaluation of the walkability of a community and its effects on physical activity and health status of the residents in China could shed light on urban design, laying a foundation for future urban planning policy and physical activity promotion interventions. Additionally, there is a gap of research on the influences of walkability on physical activity in a hilly city. This protocol is an observational, prospective cohort study of participants who receive health examination in the First Affiliated Hospital to Army Medical University. The aim of this study is to analyse the relationships among walkability, physical activity and obesity in the residents in Chongqing for future urban planning reference. Previous literature shows lower hilliness is associated with enhanced physical health. ${ }^{32}$ Our research hypothesis is that high WalkScore will be associated with the decrease of BMI under the context of a hilly city. The daily walking steps and metabolic profiles will be the mediators through the effect pathway from WalkScore to BMI.

We illustrate our hypothesis of causal diagram in online supplemental figure 1. Obesity and overweight as well as daily walking steps are the primary outcomes. WalkScore is the exposure variable. Daily walking steps and metabolic profiles are the mediator from WalkScore to obesity. ${ }^{93} 34$ Job and education are possible confoundings between WalkScore and daily walking steps. ${ }^{35}$ Physical activity is possible confounding between daily walking steps and metabolic profiles. ${ }^{96}$ Online food order habit is possible confounding between WalkScore and metabolic profiles. Eating habit, smoking and alcohol consumption are other factors, which will influence metabolic profiles. ${ }^{37-39}$

\section{MATERIALS AND METHODS}

\section{Study design and setting}

Our protocol is an observational, prospective cohort study. The location of our protocol is Chongqing, a Chinese city, with multi-commercial centres, which is characterised by a unique hilly topology with two rivers, Yangtze and Jialing. ${ }^{40}$ A map and photos with the hilly topography of Chongqing are shown in online supplemental figure 2. Blood samples, clinical data, addresses and related variables are collected prospectively from participants who receive health examination in the Health Management Centre, First Affiliated Hospital to Army Medical University, Chongqing. Blood samples are examined by the clinical laboratory of the hospital. Clinical and demographic data are recorded in the hospital's database. The daily walking steps of participants are collected by WeChat mini application. The home and workplace addresses and the part of listed variables in table 1 will be collected by a questionnaire referred to a comprehensive cohort study named China Kadoorie Biobank study. ${ }^{41}$ Participants will be recruited from October 2019 to 2020 and followed up till 2023. The recruitment period will be extended if necessary. The recruitment process can be referred 
Table 1 All measured variables

\begin{tabular}{|c|c|c|c|c|}
\hline $\begin{array}{l}\text { Variable } \\
\text { category }\end{array}$ & Name of variable & Normal limits* or categories & $\begin{array}{l}\text { Definition of } \\
\text { variables } †\end{array}$ & Sources of data \\
\hline \multirow[t]{2}{*}{$\begin{array}{l}\text { Primary } \\
\text { outcomes }\end{array}$} & Body mass index & $18.5-24 \mathrm{~kg} / \mathrm{m}^{2}$ & Outcome & $\begin{array}{l}\text { Calculate from health } \\
\text { examination data (height } \\
\text { and weight) }\end{array}$ \\
\hline & Daily walking steps in 1 month & & $\begin{array}{l}\text { Outcome and } \\
\text { mediator }\end{array}$ & WeChat mini application \\
\hline \multirow{4}{*}{$\begin{array}{l}\text { Secondary } \\
\text { outcomes }\end{array}$} & Total cholesterol & $3.1-5.7(\mathrm{mmol} / \mathrm{L})$ & Outcome & Health examination \\
\hline & Triglyceride & $0.4-1.73(\mathrm{mmol} / \mathrm{L})$ & Outcome & Health examination \\
\hline & $\begin{array}{l}\text { Low density lipoprotein } \\
\text { cholesterin }\end{array}$ & $2.07-3.1(\mathrm{mmol} / \mathrm{L})$ & Outcome & Health examination \\
\hline & $\begin{array}{l}\text { High density lipoprotein } \\
\text { cholesterin }\end{array}$ & 0.9-2 (mmol/L) & Outcome & Health examination \\
\hline $\begin{array}{l}\text { Exposure } \\
\text { variables }\end{array}$ & $\begin{array}{l}\text { WalkScore corresponding to } \\
\text { workplace address }\end{array}$ & $0-100$ & Exposure & $\begin{array}{l}\text { Calculate from } \\
\text { questionnaire information }\end{array}$ \\
\hline \multirow[t]{8}{*}{ Other variables } & Height & & & Health examination \\
\hline & Weight & & & Health examination \\
\hline & Age & 16-65 years old & $\begin{array}{l}\text { Possible } \\
\text { confounding }\end{array}$ & Questionnaire \\
\hline & Gender & Male; female & $\begin{array}{l}\text { Possible } \\
\text { confounding }\end{array}$ & Questionnaire \\
\hline & Alcohol consumption & $\begin{array}{l}\text { Giving up; never; sometimes } \\
\text { drink; frequently drink }\end{array}$ & $\begin{array}{l}\text { Other factors } \\
\text { will influence } \\
\text { outcome }\end{array}$ & Questionnaire \\
\hline & Online food order habit & $\begin{array}{l}\text { Never; sometimes order; } \\
\text { frequently order }\end{array}$ & $\begin{array}{l}\text { Possible } \\
\text { confounding }\end{array}$ & Questionnaire \\
\hline & Eating diet & Not applicable & $\begin{array}{l}\text { Other factors } \\
\text { will influence } \\
\text { outcome }\end{array}$ & Questionnaire \\
\hline & Physical activity & Not applicable & $\begin{array}{l}\text { Possible } \\
\text { confounding }\end{array}$ & Questionnaire \\
\hline
\end{tabular}

*'Normal limits' means in these limits, the corresponding condition is normal, otherwise, it suggests there may be some health concerns or some errors.

†The definition of variables can be referred to online supplemental figure 1.

to figure 1 and the timeline is shown in online supplemental table 1. Moreover, we will include the participants who decided an examination appointment before health examination day if he/she meets the inclusion/exclusion criteria. We need to require this kind of participants to provide home and workplace addresses on the first visit and fill the questionnaire on the health examination day.

In the baseline, the specific recruitment and data collection procedure are as follows. Stage 1: after participants signed informed consent, we collected demographic data 

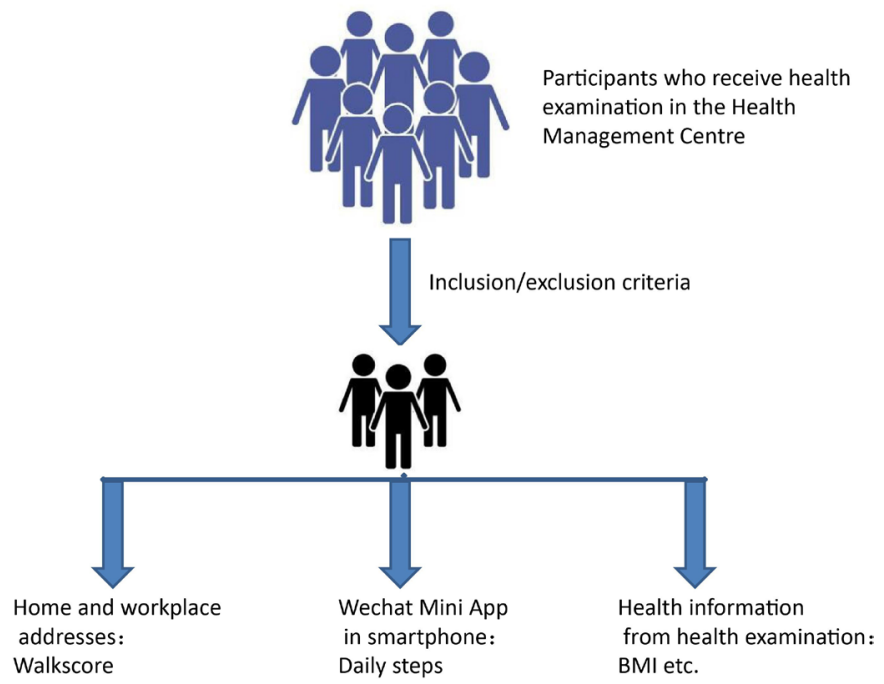

Figure 1 Flow chart of study. BMI, body mass index.

and home/workplace addresses information in 2019 October. The recruitment time will be extended to 2020 May. Stage 2: Before or on the health examination day in 2020 March-May, we will check the inclusion/exclusion criteria and screen the participants for the first time. Stage 3: collecting questionnaire on the health examination day in 2020 March-May. Stage 4: requesting participants to instal WeChat mini application and endow authorisation on the health examination day in 2020 March-May. Stage 4: health examination including blood sample collection and height/weight measurement will be conducted. Stage 5: daily steps in 30 days will be collected after the day of health examination. Stage 6: the inclusion/exclusion criteria will be checked second after data collection.

In the three times follow-ups in 2021, 2022 and 2023, the data collection procedure is similar to those in the baseline. Stage 1: collecting demographic data and updating home/workplace addresses information. Stage 2: collecting questionnaire. Stage 3: requesting participants to instal WeChat mini application and endow authorisation. Stage 4: health examination including blood sample collection and height/weight measurement will be conducted. Stage 5: daily steps in 30 days will be collected after the day of health examination.

\section{Participants}

This is an open cohort study. Participants are eligible for inclusion if they satisfy the following criteria: an age between 16 and 65, using smartphones, habitual residents in the downtown area of Chongqing.

The exclusion criteria will be: (1) participants with the symptoms or signs of cardiovascular and cerebrovascular diseases, such as chest tightness, shortness of breath and even chest pain, especially those whose symptoms get worse when climbing stairs or walking fast; (2) participants with diagnosed heart diseases, such as coronary heart diseases, hypertensive heart diseases, valvular heart diseases and pulmonary heart diseases, who need to exercise based on principles of cardiac rehabilitation; (3) participants with other severe complications of diabetes, such as those with vision severely affected by eye diseases, those with balancing ability affected by peripheral neuropathy, those with diabetic foot and those with renal dysfunction; (4) participants whose movement is affected by musculoskeletal disorders, for example, patients with musculoskeletal disorders and cardiopulmonary dysfunction; (5) participants who refuse to provide corresponding information, or are not able to complete the questionnaire and health examination (this item should also be checked in data cleaning stage); (6) participants who plan to migrate to other areas or leave for a long time (more than 1 year); (7) participants with secondary morbid obesity caused by congenital diseases, metabolic diseases, neurologic diseases and endocrine diseases. After checking the inclusion/exclusion criteria, the participants are planned to be recruited. Participants must be able to sign written informed consent after acknowledging the benefits and risks of this study. Participants information will be checked and the follow-ups will be traced by the health managers and nurses in the Health Management Centre.

The number of the sample size was calculated using the following formula:

$$
n=\frac{\left(z_{\alpha} \sqrt{2 \bar{p} \bar{q}}+z_{\beta} \sqrt{p_{0} q_{0}+p_{1} q_{1}}\right)^{2}}{\left(p_{1}-p_{0}\right)^{2}}
$$

The parameters used in the calculation are: $\mathrm{p}_{0_{6}}$ (the obesity prevalence in control group) as $10.3 \%,{ }^{6}$ the supposed risk ratio (RR) between groups with high WalkScore and low WalkScore as $0.5, \alpha=0.05$ and $1-\beta=0.9$. In this formula, $\mathrm{p}_{1}=\mathrm{p}_{0} \times \mathrm{RR}=5.15 \%, \overline{\mathrm{p}}=\left(\mathrm{p}_{0}+\mathrm{p}_{1}\right) / 2, \overline{\mathrm{q}}=1-\overline{\mathrm{p}}$ , $\mathrm{q}_{0}=1-\mathrm{p}_{0}$ and $\mathrm{q}_{1}=1-\mathrm{p}_{1}, \mathrm{Z}_{\alpha}=1.96$, and $\mathrm{Z}_{\beta}=1.282$. Based on these parameters, the sample size in exposure group and control group should be 400 , respectively. Concerning the possibility of loss of follow-up, we increased the sample size by $10 \%$ to 440 participants in each group. The final sample size is 880 in total.

\section{Measures}

The questionnaire (full version of the questionnaire is attached in online supplemental file 1) filled by participants under nurses' guidance includes the questions of participant demographics, exposure and lifestyle factors. The measured variables, primary outcome and secondary outcomes, exposure variables, as well as possible confoundings are listed in table 1 . The variables in detail are shown in online supplemental file 2. The relationships among different variables are illustrated in a causal diagram in online supplemental figure 1.

During the process of data collection, the following data were collected by the questionnaire and health examination procedure as well as WeChat mini application:

1. Primary outcomes: BMI, and everyday walking steps are recorded by a WeChat mini application. Every year, the daily walking steps in 30 days will be collected after health examination in the hospital. BMI was calculated by the weight in kilograms divided by the square of the height in metres. Overweight and obesity were defined 
as a BMI of $24-27.9 \mathrm{~kg} / \mathrm{m}^{2}$ and a $\mathrm{BMI} \geq 28 \mathrm{~kg} / \mathrm{m}^{2}$, respectively. ${ }^{4}$ The participants will authorise the application in order to allow the researchers in this study to obtain the daily walking steps in 30 days collected by the WeChat mini application. (They only need to record walking steps of 30 days once a year.)

2. Secondary outcomes: metabolic profiles by blood tests; for example, cholesterol levels and blood glucose. Body composition was measured by a machine named inbody 220, when doing the measurement in which, the participants will stand on the machine without shoes and hold the two poles of the machine for $5 \mathrm{~min}$.

3. Exposure variables: Walkscores, which will be calculated based on the workplace address and residential address of the participants.

4. Participant demographics: age, gender, height, marital status and education.

5. Lifestyle factors: smoking status, alcohol consumption, online food order habit, eating diet and physical activity.

6. Identification of non-communicable diseases: for example, hypertension, coronary artery disease and diabetes.

\section{Biological samples and assay methods}

The blood samples are collected by nurses in the Health Management Centre in the morning. The participants should be fasting for 12-14hours before health examination. A sum of $5 \mathrm{~mL}$ blood was collected in the yellow tube with inert separating gel for cholesterol and glucose testing. A total of $2 \mathrm{~mL}$ blood for blood routine test was stored in a purple tube with EDTA as anticoagulant. The blood samples are analysed by automated biochemical analyser, with the series number of Beckman AU5811. Total cholesterol was tested by the cholesteroloxidase enzyme method. Triglyceride was tested by the glycerol phosphate dehydrogenase and peroxidase method.

\section{Physical examination}

The physical examination included the measurement of height, body weight, blood pressure and body component following the guidelines of the Health Management Centre. The blood pressure was evaluated by electronic sphygmomanometer (Omron, type: B-203RV III C). The machine Inbody 220 was used to analyse body component, including the proportion of water, protein, mineral salt and fat.

\section{WalkScore}

WalkScore measures pedestrian friendliness by analysing the distance to points of interest and the weights of points of interest. Data sources are from Google, Factual, Great Schools, Open Street Map, the US Census, Localeze and places added by the WalkScore user community. ${ }^{42}$ The algorithm of WalkScore is not disclosed in its official website. The formula ${ }^{43}$ of WalkScore illustrated in Tsinghua University is

\begin{tabular}{llllll}
\hline Table 2 & Weights of different amenities & \\
\hline $\begin{array}{l}\text { Amenity's } \\
\text { name }\end{array}$ & Weight & $\begin{array}{l}\text { Amenity's } \\
\text { name }\end{array}$ & Weight & $\begin{array}{l}\text { Amenity's } \\
\text { name }\end{array}$ & Weight \\
$\begin{array}{l}\text { Convenience } \\
\text { store }\end{array}$ & 3 & $\begin{array}{l}\text { Café/ } \\
\text { teahouse }\end{array}$ & 2 & School & 1 \\
$\begin{array}{l}\text { Restaurant } \\
\text { Shop }\end{array}$ & 3 & Bank & 1 & Bookstore & 1 \\
& 2 & Park & 1 & $\begin{array}{l}\text { Entertainment } \\
\text { places }\end{array}$ & \\
\hline
\end{tabular}

$$
\sum_{\mathrm{i}=1, \mathrm{j}=1}^{\mathrm{m}, \mathrm{n}}\left(\mathrm{W}_{\mathrm{i}} * \mathrm{~S}_{\mathrm{i}, \mathrm{j}} * \mathrm{DD}_{\mathrm{j}}\right) * \frac{100}{15}
$$

$\mathrm{W}_{\mathrm{i}}$ is the weight of one kind of amenity. Table 2 shows the weights of different amenities.

The letter of i stands for different kinds of amenities. The letter of $\mathrm{j}$ stands for different walking distance. $\mathrm{S}_{\mathrm{i}, \mathrm{j}}$ stands for service scope of a specific amenity. $\mathrm{DD}_{\mathrm{j}}$ stands for the attenuation coefficient based on distance from the calculated point to an amenity. Table 3 shows the attenuation coefficients based on the distances from the calculated point to an amenity.

The calculation of WalkScore is free, to obtain which we could type the name of calculated point into the official website/cellphone application and wait for the score (www.WalkScore.com). The limit of the score is $0-100$. The WalkScore of residential address and workplace address will be calculated separately.

The following table 4 describes the meanings of different WalkScore.

\section{WeChat mini application}

WeChat is a cellphone application for communication used by more than a billion people. ${ }^{44}$ The customers of it can send voice, video, photos and text. On the basis of WeChat and its great number of users, the company of WeChat opens the resources to the public of developing different kinds of WeChat mini applications. Users could link its WeChat ID to WeChat mini application without download instalment package and achieve data sharing through WeChat mini application. WeChat could also record daily step data from users' cellphones after user's agreement. Through WeChat mini application, we could extract the daily walking steps of WeChat users in 1 month after customer agreement. After we develop the WeChat mini application following the guideline from

\begin{tabular}{ll}
\hline Table 3 & Attenuation coefficients based on the distances \\
\hline Distances $(\mathbf{m})$ & Attenuation coefficients \\
\hline$<400$ & 1 \\
$400-800$ & 0.9 \\
$800-1200$ & 0.55 \\
$1200-1600$ & 0.25 \\
$1600-2400$ & $\begin{array}{l}0.08 \\
>2400\end{array}$ \\
& $\begin{array}{l}\text { Out of distance scope, which will not be } \\
\text { calculated. }\end{array}$ \\
\hline
\end{tabular}




\begin{tabular}{|c|c|}
\hline WalkScore & Description \\
\hline $90-100$ & $\begin{array}{l}\text { Walker's paradise: daily errands do not require } \\
\text { a car. }\end{array}$ \\
\hline $70-89$ & $\begin{array}{l}\text { Very walkable: most errands can be } \\
\text { accomplished on foot. }\end{array}$ \\
\hline $50-69$ & $\begin{array}{l}\text { Somewhat Walkable: some errands can be } \\
\text { accomplished on foot. }\end{array}$ \\
\hline $25-49$ & Car-dependent: most errands require a car. \\
\hline $0-24$ & Almost all errands require a car. \\
\hline
\end{tabular}

WeChat and publish it, the participants could open the WeChat mini application in their WeChat and signed a second consent to agree that they are willing to allow us to extract daily steps on the platform of WeChat. Then, the customers' daily step information will be delivered to our datasets automatically. The obtained data will be consistent with the records in participants' cell phones.

\section{Statistical methods}

The data analysis will be conducted after data collection in 2020. The prospective analysis will be implemented in 2023. Stata (V.14.0, Stata Corp., College Station, Texas, USA) and R (V.4.0.2) will be used for data analysis. Descriptive statistics will be performed to analyse the distribution of the data. Missing data will be addressed by deletion or last observation carried forward based on specific case status. Single variable analysis will be implemented to analyse the correlations between exposures, possible confoundings (ie, online food order habit, education, job, physical activity) and outcomes. The participants will be divided into five groups by the categories of the WalkScore with regard to workplace address and residential address, respectively. The lifestyle factors and outcomes will be compared among groups. All the variables in causal diagrams will be compared between baseline and follow-ups. T-test will be used for comparing the difference of the continuous variables in two groups and $\chi^{2}$ test or analysis of variance will be used for comparing the difference of categorial variables in different groups. Multivariate linear regression will be conducted taken BMI and daily walking steps as dependent variables, respectively, as cross-sectional analyses, after data collection in 2020. Sensitivity analysis will be implemented by bootstrap method. With replacement from the original dataset, the bootstrap method enables estimation of the accuracy of an estimator by random sampling. Further longitudinal analyses with $\mathrm{G}$ estimation and inverse probability weight analysis will be conducted after data collection in 2023 in order to take into account the effects of confounders whose conditions may change over time. The first step is to determine the ranges and variations of the independent variables, which are input into our multivariate linear regression. The second step is to generate independent variables based on the Sobol sequence by R package 'randtoolbox'. The final step is to collect and process the simulation results, which can be used in sensitivity analysis through conducting multivariate linear regression. ${ }^{45}$

\section{PATIENT AND PUBLIC INVOLVEMENT}

Our study is an observational study without intervention on participants. The development of the research question and outcome measures were informed by participants' priorities, experience and preferences on the basis of informed consents. There is no participants' involvement in the study design. We recruit participants when conducting the study, but participants would not be the conductor of the study. The results are planned to disseminate to study participants.

\section{ETHICS AND DISSEMINATION}

The Protocol is approved by the Ethics Committee of the First Affiliated Hospital to Army Medical University (KY201839). All the participants will receive consultation about the benefits and possible risks of the study from health managers and nurses, and endow written informed consent before enrollment. All the participants will be informed that they can withdraw from the study at any time for any reason. The withdrawal cases will be discarded and related information will be deleted from the database of the study.

The sample volume of blood for the study is 11 per participant-visit and maximum 55 for 5 years. The blood sampling process is part of the procedure of health examination and this study acquires the data use authority after the recruitment. The participants will be contacted and informed the results of the health examination. The researchers of this study will be responsible for implementing the study adhering to the Declaration of Helsinki.

We plan to analyse and publish study results according to the Strengthening the Reporting of Observational Studies in Epidemiology guidelines. Results will be published in international and peer-reviewed scientific journals. Negative, positive, conclusive or inconclusive results will be published.

\section{STUDY STATUS}

We collected demographic data, home addresses and workplace addresses of participants in October 2019. We plan to check previous data and collect the data of health examination and questionnaire of participants in March-May 2020 and daily walking steps of participants by WeChat mini application in 2020 (in 1 month after health examination). We will continue follow-up in 2021-2023. The follow-up will be sustained by contacting participants and requiring health examination by phone. Currently, the daily walking steps collector of the WeChat mini application has been developed. The study was registered in Chinese clinical trial registration. The date of the 
study in a timeline is shown in online supplemental table 1 . There will be six waves of data collection.

\section{DISCUSSION AND POTENTIAL LIMITATIONS}

This observational and prospective study could innovatively provide evidence of the relationship among walkability, obesity and physical activity in China. It will also provide evidence of the influence of the built environment on physical activity in a hilly city, Chongqing. We hypothesised that the walkability, physical activity and obesity status are strongly associated with each other. The use of WeChat mini application in data collection process has a lot of advantages. Through extracting data from cellphones' records, the data collection is very convenient and cost-effective, which eliminates the errors of manual typing. The participants will sign informed consents before recruitment and sign an agreement to endow WeChat mini application to collect their daily steps before the use of WeChat, in which way we could ensure the process meets the ethic requirements.

There are some limitations in the collection of physical activity. The WeChat mini application can only record the daily walking steps when the participants walk with their phone. Like other studies, activities without carrying phones such as swimming and ball games will not be recorded in the data collection procedure. ${ }^{15}$ Moreover, more than 30 days' collection needs second authorisation (the maximum data collection time is 30 days after one authorisation) which is less adherent; thus the researchers could only collect the data of 30 days in 1 year for convenience. In order to compensate for this limitation, the participants will be recruited all year round and the researchers will ask for a second authorisation of daily step collection in the follow-up visit. In terms of season, the season when we do the data collection may also influence the number of daily steps. We will consider the season as a confounder in future data analysis.

Moreover, WalkScore is based on an online calculation website which has not opened the algorithm officially. Other walkability evaluation tools such as Pedestrian Environment Quality Index depend on the evaluation of geographic information system, the score process of which is relatively clean; however, the practice is more complex. ${ }^{46-48}$ Thus, we decide to choose WalkScore for the exploratory study. If the results could indicate a strong relationship between walkability and obesity, we could further analyse the specific component factors such as the diversity of points of interests of walkability in the following analysis.

Acknowledgements Thanks to Dr Zhizhong Gong and Dr Baogi Fan for their suggestions of this study. Thanks to patient/participant advisors in the Health Management Centre for their assistance. Thanks to SC's friends Sarah HigbeeTindell, Chu Yu and Qingya Wu for writing assistance of grammar modification.

Contributors SC and YZ are joint first authors. SC contributed to study concept and design. SC wrote the first draft of the protocol manuscript. ZC supervised the process. YZ and JS revised the manuscript after feedback from all authors. YZ coordinates the conducting of this study. All authors reviewed the manuscript and approved the final version of the manuscript.

Funding The authors have not declared a specific grant for this research from any funding agency in the public, commercial or not-for-profit sectors.

Map disclaimer The depiction of boundaries on this map does not imply the expression of any opinion whatsoever on the part of BMJ (or any member of its group) concerning the legal status of any country, territory, jurisdiction or area or of its authorities. This map is provided without any warranty of any kind, either express or implied.

Competing interests None declared.

Patient and public involvement Patients and/or the public were not involved in the design, or conduct, or reporting, or dissemination plans of this research.

Patient consent for publication Not required.

Provenance and peer review Not commissioned; externally peer reviewed.

Open access This is an open access article distributed in accordance with the Creative Commons Attribution Non Commercial (CC BY-NC 4.0) license, which permits others to distribute, remix, adapt, build upon this work non-commercially, and license their derivative works on different terms, provided the original work is properly cited, appropriate credit is given, any changes made indicated, and the use is non-commercial. See: http://creativecommons.org/licenses/by-nc/4.0/.

ORCID iD

Zongtao Chen http://orcid.org/0000-0001-6720-9827

\section{REFERENCES}

1 Gregg EW, Shaw JE. Global health effects of overweight and obesity. N Engl J Med 2017;377:80-1.

2 GBD 2015 Obesity Collaborators, Afshin A, Forouzanfar MH, et al. Health effects of overweight and obesity in 195 countries over 25 years. N Engl J Med 2017;377:13-27.

3 Wang YF, Sun MX, Xue H, et al. [Understanding the China blue paper on obesity prevention and control and policy implications and recommendations for obesity prevention and control in China]. Zhonghua Yu Fang Yi Xue Za Zhi 2019;53:875-84.

4 Hu L, Huang X, You C, et al. Prevalence of overweight, obesity, abdominal obesity and obesity-related risk factors in southern China. PLoS One 2017:12:e183934.

5 Wang Y, Mi J, Shan X-Y, et al. Is China facing an obesity epidemic and the consequences? the trends in obesity and chronic disease in China. Int J Obes 2007;31:177-88.

6 Shuping Z. Changes in prevalence of overweight and obesity in a community in Chongqing from 2003-2013. Chongqing Medicine 2017;29:4108.

7 Stringhini S, Carmeli C, Jokela M, et al. Socioeconomic status and the $25 \times 25$ risk factors as determinants of premature mortality: a multicohort study and meta-analysis of 1.7 million men and women. Lancet 2017;389:1229-37.

8 GBD 2015 Risk Factors Collaborators. Global, regional, and national comparative risk assessment of 79 behavioural, environmental and occupational, and metabolic risks or clusters of risks, 1990-2015: a systematic analysis for the global burden of disease study 2015. Lancet 2016;388:1659-724.

9 Akinci B, Yeldan I, Celik S, et al. Physical activity indicators, metabolic biomarkers, and comorbidity in type 2 diabetes. Res $Q$ Exerc Sport 2019;90:690-8.

10 World Health Organization. Physical inactivity: a global public health problem, 2019.

11 Lee I-M, Shiroma EJ, Lobelo F, et al. Effect of physical inactivity on major non-communicable diseases worldwide: an analysis of burden of disease and life expectancy. Lancet 2012;380:219-29.

12 Bauman AE, Reis RS, Sallis JF, et al. Correlates of physical activity: why are some people physically active and others not? Lancet 2012;380:258-71.

13 Sallis JF, Cerin E, Conway TL, et al. Physical activity in relation to urban environments in 14 cities worldwide: a cross-sectional study. Lancet 2016;387:2207-17.

14 Kärmeniemi M, Lankila T, Ikäheimo T, et al. The built environment as a determinant of physical activity: a systematic review of longitudinal studies and natural experiments. Ann Behav Med 2018;52:239-51.

15 Althoff T, Sosič R, Hicks JL, et al. Large-scale physical activity data reveal worldwide activity inequality. Nature 2017;547:336-9.

16 Porter AK, Rodríguez DA, Frizzelle BG, et al. The association between neighborhood environments and physical activity from 
pregnancy to postpartum: a prospective cohort study. J Urban Health 2019;96:703-19.

17 Murillo R, Reesor LM, Hernandez DC, et al. Neighborhood Walkability and aerobic physical activity among Latinos. Am J Health Behav 2019;43:802-11.

18 Larouche R, Blanchette S, Faulkner G, et al. Correlates of children's physical activity: a Canadian multisite study. Med Sci Sports Exerc 2019;51:2482-90.

19 Amagasa S, Inoue S, Fukushima N, et al. Associations of neighborhood walkability with intensity- and bout-specific physical activity and sedentary behavior of older adults in Japan. Geriatr Gerontol Int 2019;19:861-7.

20 Jia X, Yu Y, Xia W, et al. Cardiovascular diseases in middle aged and older adults in China: the joint effects and mediation of different types of physical exercise and neighborhood greenness and walkability. Environ Res 2018;167:175-83.

21 Nightingale CM, Limb ES, Ram B, et al. The effect of moving to East village, the former London 2012 Olympic and Paralympic Games athletes' village, on physical activity and adiposity (enable London): a cohort study. Lancet Public Health 2019;4:e421-30.

22 Chudyk AM, McKay HA, Winters M, et al. Neighborhood walkability, physical activity, and walking for transportation: a cross-sectional study of older adults living on low income. BMC Geriatr 2017;17:82.

23 Sun Z, Lai KY, Bell S, et al. Exploring the associations of walking behavior with neighborhood environments by different life stages: a cross-sectional study in a smaller Chinese City. Int J Environ Res Public Health 2019;17:237.

24 Sarkar C, Webster C, Gallacher J. Neighbourhood walkability and incidence of hypertension: findings from the study of 429,334 UK Biobank participants. Int J Hyg Environ Health 2018;221:458-68.

25 Zandieh R, Flacke J, Martinez J, et al. Do inequalities in neighborhood Walkability drive disparities in older adults' outdoor walking? Int J Environ Res Public Health 2017;14

26 Jeffrey D, Boulangé C, Giles-Corti B, et al. Using walkability measures to identify train stations with the potential to become transit oriented developments located in walkable neighbourhoods. $J$ Transp Geogr 2019;76:221-31.

27 Creatore MI, Glazier RH, Moineddin R, et al. Association of neighborhood walkability with change in overweight, obesity, and diabetes. JAMA 2016;315:2211-20.

28 James P, Kioumourtzoglou M-A, Hart JE, et al. Interrelationships between walkability, air pollution, Greenness, and body mass index. Epidemiology 2017;28:780-8.

29 Yu R, Cheung O, Lau K, et al. Associations between perceived neighborhood Walkability and walking time, wellbeing, and loneliness in community-dwelling older Chinese people in Hong Kong. Int J Environ Res Public Health 2017;14

30 Michanowicz DR, Williams SR, Buonocore JJ, et al. Population allocation at the housing unit level: estimates around underground natural gas storage wells in $\mathrm{PA}, \mathrm{OH}, \mathrm{NY}, \mathrm{WV}, \mathrm{MI}$, and CA. Environ Health 2019;18:58.
31 Brath H, Kim SJ, Savage RD, et al. Neighborhood walkability of retirement homes: a cross-sectional cohort study. J Am Med Dir Assoc 2019;20:105-6.

32 Zhao Y, Chung P-K. Neighborhood environment walkability and health-related quality of life among older adults in Hong Kong. Arch Gerontol Geriatr 2017;73:182-6.

33 Chen B-I, Hsueh M-C, Rutherford R, et al. The associations between neighborhood walkability attributes and objectively measured physical activity in older adults. PLoS One 2019;14:e222268.

34 Rastović M, Srdić-Galić B, Barak O, et al. Aging, heart rate variability and metabolic impact of obesity. Acta Clin Croat 2019;58:430-8.

35 Cerin E, Conway TL, Barnett A, et al. Development and validation of the neighborhood environment walkability scale for youth across six continents. Int J Behav Nutr Phys Act 2019;16:122.

36 Fini NA, Bernhardt J, Holland AE. Low gait speed is associated with low physical activity and high sedentary time following stroke. Disabil Rehabil 2019:1-8.

37 Martinez-Ferran M, de la Guía-Galipienso F, Sanchis-Gomar F, et al. Metabolic impacts of confinement during the COVID-19 pandemic due to modified diet and physical activity habits. Nutrients 2020;12

38 Nelson NG, Weingarten MJ, Law WX, et al. Joint and separate exposure to alcohol and $\Delta^{9}$-tetrahydrocannabinol produced distinct effects on glucose and insulin homeostasis in male rats. Sci Rep 2019;9:12025.

39 Raal FJ, Tuomilehto J, Sposito AC, et al. Treatment effect of alirocumab according to age group, smoking status, and hypertension: pooled analysis from 10 randomized odyssey studies. J Clin Lipidol 2019;13:735-43.

40 Zhao Y, Tomita M, Hara K, et al. Effects of topography on status and changes in land-cover patterns, Chongqing City, China. Landscape Ecol Eng 2014;10:125-35.

41 Lv J, Qi L, Yu C, et al. Consumption of spicy foods and total and cause specific mortality: population based cohort study. BMJ 2015;351:h3942.

42 WalkScore. Walk score methodology, 2020.

43 Long Y. The large-scale calculation of "walkscore" of main cities in China. New Architecture 2018;3:4-8.

44 Tencent. Wechat official website, 2020.

45 Tian W, Song J, Li Z, et al. Bootstrap techniques for sensitivity analysis and model selection in building thermal performance analysis. Appl Energy 2014;135:320-8.

$46 \mathrm{Kim} \mathrm{H}$, Choi Y, Ma J, et al. The neighborhood environment Walkability scale for the Republic of Korea: reliability and relationship with walking. Iran J Public Health 2016;45:1427-35.

47 Adlakha D, Hipp JA, Brownson RC. Adaptation and evaluation of the neighborhood environment Walkability scale in India (NEWS-India). Int J Environ Res Public Health 2016;13:401.

48 Messer LC, Jagai JS, Rappazzo KM, et al. Construction of an environmental quality index for public health research. Environ Health 2014;13:39. 